\title{
Demand-side Management Programs - A joint environmental protection action. Case study: The lighting system in the Campus of the University POLITEHNICA of Bucharest
}

\author{
Mircea Scripcariu ${ }^{1}$, Ioan Sevastian Bitir-Istrate ${ }^{2}$, Cristian Gheorghiu ${ }^{3 *}$, Ștefăniță Pluteanu ${ }^{3}$ \\ and Aida Maria Neniu ${ }^{4}$ \\ ${ }^{1}$ Associate Prof., Dept. of Energy Production and Use, University POLITEHNICA of Bucharest, \\ Romania \\ ${ }^{2}$ Associate Prof., Dept. of Energy Production and Use, University POLITEHNICA of Bucharest,
Romania \\ ${ }^{3} \mathrm{PhD}$. Student, Dept. of Energy Production and Use, University POLITEHNICA of Bucharest, \\ Romania \\ ${ }^{3} \mathrm{PhD}$. Student, Dept. of Energy Production and Use, University POLITEHNICA of Bucharest, \\ Romania \\ ${ }^{4} \mathrm{PhD}$. Student, Dept. of Energy Production and Use, University POLITEHNICA of Bucharest, \\ Romania
}

\begin{abstract}
The current development of Smart Grids, combined with the pressure enforced by national legislation as a direct effect of the 2012/27/EU and the 2018/844/EU Directives and the ever-growing energy demand lead to a new set of challenges for both the end-users and the utility companies, under the form of optimizing the EPIs (Energy Performance Indicators), reducing the Environmental Impact and flattening the Power Demand Curve. In this paper, the economical viability and the potential environmental impact reduction obtained by implementing a DSM (Demand-Side Management) program in the Campus of the University POLITEHNICA of Bucharest were analysed. The energy boundary consisted of all the 26 Student Dorms and the main Significant Energy Use) consisted of the lighting system. Four different scenarios were conceived, taking into account the initial investment and the energy savings sharing between the end-user and the Utility Company. Based on these scenarios, a technical-economic model is presented. Using the data gathered on-site and the DSM program mode, relevant results were obtained and a development solution for such projects was proposed. In the final part of the paper, the predicted Environmental Impact Reduction was quantified and analysed, under the form of the Carbon Footprint generated, respectively avoided by implementing the most economically efficient DSM program development solution.
\end{abstract}

\footnotetext{
* Corresponding author: gheorghiu.cristian.k@gmail.com
} 


\section{Introduction}

DSM consists in the proper planning, implementation and monitoring of energy use activities which are destined to encourage the end-users to modify and optimize the energyconsumption levels and behaviour.

In the past, the main purpose of implementing DSMs was to ensure an efficient energy supply and economically efficient solutions in order to delay the necessity of installing additional Power Generation sources [1], as a result of the ever-growing energy demand.

However, due to the changes that occur in the industrial sector, the emergence of new consumers (e.g. Office Buildings, Apartment Buildings etc.), DSM became a tool that can be used by the Utility Companies in order to improve the quality of their services.

In essence, DSMs are programs and activities that modify the power-demand curve by offering modern load-management solutions, in the form energy performance indicators improvement solutions.

As a cumulative result of the liberalization of the energy market, the energy efficiency targets and the targets set by the European Directives with regard to the reduction of the Carbon Footprint, DSMs are becoming more and more attractive. The main objective of this paper is to prove the necessity, the benefits and the economic efficiency of such Programs.

\section{Romanian national legislation and strategy regarding energy efficiency}

Improving the EPIs is the main objective of Romania's energy strategy, considering the major contribution that they have in assuring the end-user power supply, the competitive character of the aforementioned services and the reduction of the environmental impact.

The main EPI used by all the Member States is the EI (Energy Intensity) [2-3]. Thus, by following EU's Directives 2012/27/EU and 2018/844/EU, the necessity of improving the existing national policies is obvious, as it can be seen in Table 1 .

Table 1. The potential energy consumption reduction for different end-use sectors [1].

\begin{tabular}{|c|c|c|}
\hline Sector & $\begin{array}{c}\text { Share in total energy } \\
\text { consumption [\%] }\end{array}$ & $\begin{array}{c}\text { Energy Use Reduction } \\
\text { Potential [\%] }\end{array}$ \\
\hline Industry & 31 & 13 \\
\hline Buildings & 36 & 41.5 \\
\hline Transport & 22 & 31.5 \\
\hline Services & 11 & 14 \\
\hline
\end{tabular}

The case study is based on the Buildings Sector. The available EPIAs for the Buildings Sector differ depending on the building type and destination but cover the entire energy cycle - primary resources, generation, transport, distribution, supply and end-use.

The main energy use for buildings is associated to the HVAC (Heating, Ventilation and Air Conditioning) and the lighting systems.

Based on [1], 87.2\% of the energy used in Buildings is used for heating, hot water and cooking, the difference of $12.8 \%$ being used lighting and powering up house appliances. Also, as [4] has shown, in $2015,82.7 \%$ of final energy consumption in buildings was supplied by fossil fuels. 
The estimated energy saving potential generated by the lighting systems is evaluated [4] at approximatively 160 EJ or 3,821.54 Mt.o.e. in the 2018 - 2040 time-frame, worldwide.

For the 2020-2030 time-frame, the European Union set up the energy efficiency target of $30 \%$ by $40 \%$ Carbon Footprint Reduction/27\% Renewable Energy Share in Energy Consumption/30\% Energy Efficiency Improvement set by the 2016 EU Commission package of measures, to which an environmental impact reduction of $40 \%$ is associated.

Romania's Energy Strategy is centred on the needs and interests of all end-users (household, commercial and public administration). It focuses on the fact that these needs and interests are diverse and perpetually changing and evolving [5]. In order to ensure the implementation of major EPIAs a stable and transparent methodology is required, based on a realist approach with regard to the set targets.

\section{Theoretical aspects of DSM Programs}

The implementation method of a DSM Program mainly depends on the objective that the said Program sets. As previously stated, the usual main objectives of DSM Programs is the flattening of the Power Demand Curve and the reduction of the energy consumption, but is also dependent on several other factors, such as:

- Financial restrictions of the end-user or the energy supplier;

- The existence / absence of financial incentives;

- The potential of achieving economical or social objective targets by implementing the Program;

- The wish of the energy supplier (or national Government) to persuade end-users to implement DSM Programs.

The fundamental characteristic of any DSM Program is the fact that different sectors of society perceive different groups of costs and benefits associated to them.

In order to economically evaluate the viability of a DSM Program a number of tests were developed and applied by various Energy Suppliers worldwide. The main that are briefly presented in Table 2 are all based on the classic Discounted Total Cost criterion.

Table 2. Tests used for the economic analysis of DSM programs [5].

\begin{tabular}{|c|c|c|c|}
\hline No. & Test Name & Formula & Unit \\
\hline 1 & Participants Benefit (PB) & $\mathrm{PB}=\Delta \mathrm{B}+\mathrm{S}-\mathrm{C}_{\text {participants }}$ & EUR \\
\hline 2 & Energy Supplier Benefit (ESB) & $\mathrm{ESB}=\mathrm{AC}-\mathrm{C}_{\mathrm{ES}}-\mathrm{S}$ & EUR \\
\hline 3 & Total Resource Cost (TRC) & $\mathrm{TRC}=\mathrm{AC}-\mathrm{CES}-\mathrm{C}_{\text {participants }}$ & EUR \\
\hline
\end{tabular}

where:

$\Delta \mathrm{B}$ - the energy bill reduction;

$\mathrm{S}$ - stimulants paid by the energy supplier to the DSM Program participants;

$\mathrm{C}_{\text {participants }}$ - the end-user share of the DSM Program Costs;

$\mathrm{C}_{\mathrm{ES}}$ - the Energy Supplier share of the DSM Program Costs;

AC - Energy Supplier Avoided Costs as a result of implementing the DSM Program.

\subsection{Participants Benefit (PB) Test}


This first test includes the quantifiable costs and benefits generated by a DSM Program, from the end-user Point of View. It evaluates the economic attractiveness of the Program for the end-users, by determining the present value of the project with (1):

$$
\mathrm{PB}=\Delta \mathrm{B}+\mathrm{S}-\mathrm{C}_{\text {participants }}[\mathrm{EUR}]
$$

The Program is considered economically efficient for the end-user if $\mathrm{PB} \geq 0$.

\subsection{Energy Supplier Benefit (ESB) Test}

This test is used to measure the total cost and benefits variation for the energy supplier as a result of implementing the DSM Program. The DSM Program effect on the energy supply company is a complex one, enabling multiple opportunities to cut the costs, to improve the annual cash flow and to maintain the current activity. The test is defined by the following formula (2) and it essentially measures the energy bill variation of all end-users:

$$
\mathrm{ESB}=\mathrm{AC}-\mathrm{C}_{\mathrm{ES}}-\mathrm{S}[\mathrm{EUR}]
$$

The Program is considered economically efficient for the energy supplier if ESB $\geq 0$.

\subsection{Total Resource Cost (TRC) Test}

This test evaluates the total cost and benefit variation for the national economy, thus quantifying the impact that a DSM Program has on both the energy supply company and the end-users, by using the formula (3). This test offers a global image on the economic efficiency of the analysed DSM Program.

$$
\mathrm{TRC}=\mathrm{AC}-\mathrm{C}_{\mathrm{ES}}-\mathrm{C}_{\text {participants }}=\mathrm{ESB}+\mathrm{PB}-\Delta \mathrm{B}[\mathrm{EUR}]
$$

The Program is considered economically efficient for the national economy if $\mathrm{TRC} \geq 0$.

\section{The considered scenarios}

Based on the aforementioned theoretical considerations, four analysis scenarios were considered, based on each side's share of the investment cost and on the way that the energy savings, quantified in the reduction of the monthly energy bill, is shared between the involved entities:

$>$ Scenario A:

$\circ \quad$ The investment cost is supported integrally by the end-user $\left(\mathrm{C}_{\text {participans }}=\mathrm{I}\right.$, $\left.\mathrm{C}_{\mathrm{ES}}=0\right)$;

- $\Delta \mathrm{B}$ is constant for the entire analysis period;

\section{$>$ Scenario B:}

○ The investment cost is supported integrally by the energy supplier $\left(\mathrm{C}_{\text {participants }}=0, \mathrm{C}_{\mathrm{ES}}=\mathrm{I}\right)$;

- The energy supplier does not directly recover the investment but by the indirect benefits generated by the DSM Program;

- The end-user obtains the $\Delta \mathrm{B}$ energy bill reduction for the entire analysis period. 
Scenario C:

$\circ$ The investment cost is supported integrally by the energy supplier $\left(\mathrm{C}_{\text {participants }}=0, \mathrm{C}_{\mathrm{ES}}=\mathrm{I}\right)$;

- The share quota " $y$ " is determined by optimizing the function in order to ensure the economic viability for both sides involved in the Program;

- The energy savings are shared throughout the analysis period between the end-user and the energy supplier based on the (4) formula:

$$
\mathrm{ESV}_{\mathrm{ES}}=\mathrm{y} \cdot \Delta \mathrm{B} \cdot \mathrm{D}_{\mathrm{F}}[\mathrm{EUR}]
$$

where:

$\mathrm{ESV}_{\mathrm{ES}}$ - energy supply company quota of the energy savings value;

$\mathrm{y}$ - the share of the end-user energy savings that are paid back to the energy supply company;

$\mathrm{D}_{\mathrm{F}}-$ Discount factor.

$>$ Scenario D:

- The investment cost is supported by an " $\mathrm{x}$ " share by the end-user $\left(\mathrm{C}_{\text {participants }}=\mathrm{x} \cdot \mathrm{I}, \mathrm{C}_{\mathrm{ES}}=(1-\mathrm{x}) \cdot \mathrm{I}\right)$;

- The " $\mathrm{x}$ " share is determined by the results of the test, in order to assure the economic viability for both sides involved in the Program.

When comparing the proposed scenarios with the theoretical DSM Program, one can observe that only the second scenario satisfies the definition of a Demand - Side Management Program. The other scenarios expand the classical definition of the DSM and facilitate the integration of the aforementioned concept with the ESCO (Energy Services Company) ever-growing market, thus making the Energy Supply Company able to compete against ESCOs or even form a sort of partnership with one of them.

\section{Case Study: University POLITEHNICA Bucharest Student Dorms}

In the case study the implementation of a DSM Program for the UPB (University POLITEHNICA Bucharest) Student Dorms lighting systems was analysed. In essence, the technical-economic viability of replacing the existing lighting systems - Incandescent bulbs - with energy efficient LED (Light Emitting Diode) lamps was analysed.

Firstly, the twenty six dorms were classified based on the dorm-room capacity, the results being presented in Table 3 .

Table 3. Student Dorms in UPB Campus.

\begin{tabular}{|c|c|c|}
\hline Dorm & Room Type & Dorm Type \\
\hline P13, P14, P17, P18 & 4 beds + sink / shared bathrooms & 1 \\
\hline P15, P16, P21, P22, P23, P24, P25, P26, P27 & 2 beds + sink / shared bathrooms & 2 \\
\hline P1, P2, P3, P4, P5, P6, P7, P8, P9, P10, P11 & 4 beds + sink + bathroom & 3 \\
\hline
\end{tabular}

In order to properly analyse the viability of a DSM Program, the energy boundary must be well known and the main energy uses must be thoroughly identified.

In Fig. 1 the annual (2018) electricity consumption for all the twenty six dorms is presented. 


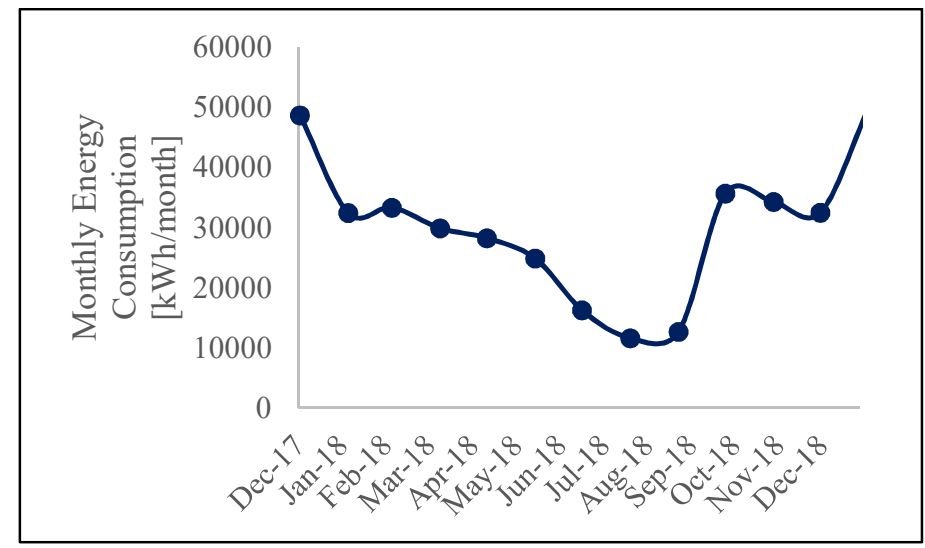

Fig. 1. 2018 electricity consumption of one of the 26 UPB Student Dorms

It can be observed from Fig. 1 that the electricity consumption registers a decreasing trend during the spring - summer period, with a minimum value in August, correlated to the minimum number of students still living in the dorms.

The analysed DSM Program targets the reduction of the lighting system electricity consumption, which amounts to a $12 \%$ percentage of the total electricity consumption. To address the bigger-share end-uses (such as household appliances), another DSM Program would have to be developed. The development would only be possible if UPB would own the aforementioned household appliances.

\subsection{Technical-economic analysis}

In order to determine the technical-economic viability of implementing the Lighting System DSM Program, the technical solutions were firstly determined. The technical and economic characteristics of the existing and the proposed lighting system is presented in Table 4.

Table 4. Existing and proposed technical solution [6-7-8]

\begin{tabular}{|c|c|c|c|}
\hline Dorm & $\begin{array}{c}\text { Dorm } \\
\text { Type }\end{array}$ & Lighting Type & $\begin{array}{c}\text { Installed Power } \\
\text { [W/pcs.] }\end{array}$ \\
\hline \multirow{2}{*}{ P13, P14, P17, P18 } & 1 & $\begin{array}{c}\text { Existent : } \\
\text { Incandescent }\end{array}$ & 180 \\
\cline { 3 - 4 } & \multirow{2}{*}{$\begin{array}{c}\text { Proposed : } \\
\text { LED }\end{array}$} & 47 \\
\hline \multirow{2}{*}{$\begin{array}{c}\text { P15, P16, P21, P22, P23, P24, P25, } \\
\text { P26, P27 }\end{array}$} & 2 & $\begin{array}{c}\text { Existent : } \\
\text { Incandescent }\end{array}$ & 96 \\
\cline { 3 - 4 } & $\begin{array}{c}\text { Proposed : } \\
\text { LED }\end{array}$ & 47 \\
\hline \multirow{2}{*}{$\begin{array}{c}\text { P1, P2, P3, P4, P5, P6, P7, P8, P9, } \\
\text { P10, P11 }\end{array}$} & \multirow{2}{*}{$\begin{array}{c}\text { Existent : } \\
\text { Incandescent }\end{array}$} & 84 \\
\cline { 3 - 4 } & & $\begin{array}{c}\text { Proposed : } \\
\text { LED }\end{array}$ & 41 \\
\hline HALLWAYS + BATHROOMS & \multirow{2}{*}{$\begin{array}{c}\text { Existent : } \\
\text { CFL }\end{array}$} & 36 \\
\cline { 3 - 5 } & & $\begin{array}{c}\text { Proposed : } \\
\text { LED }\end{array}$ & 16 \\
\hline
\end{tabular}

The economic analysis was based on the data inputs briefly presented in Table 5 . 
Table 5. Economic analysis input data.

\begin{tabular}{|c|c|c|}
\hline Input type & Value & M.U. \\
\hline Discount rate [9] & 4,5 & $\% /$ year \\
\hline Analysis Period[10] & 10 & Years \\
\hline Active Energy Price $^{*}$ & 88.38 & EUR/MWh \\
\hline Reactive Energy Price $^{*}$ & 12.84 & EUR/MVArh \\
\hline $\begin{array}{c}\text { Rated Average Lifetime for } \\
\text { Incandescent Bulbs }\end{array}$ & 1,000 & Hours \\
\hline $\begin{array}{c}\text { Rated Average Lifetime for LED } \\
\text { lights }\end{array}$ & 25,000 & Hours \\
\hline
\end{tabular}

* without VAT (Value Added Tax)

By replacing the existent Incandescent Lights with Energy Efficient LED ones, depending on the type of dorm, an energy economy of approximatively 5,200 kWh/year/dorm can be achieved, as it can be seen in Fig. 2.

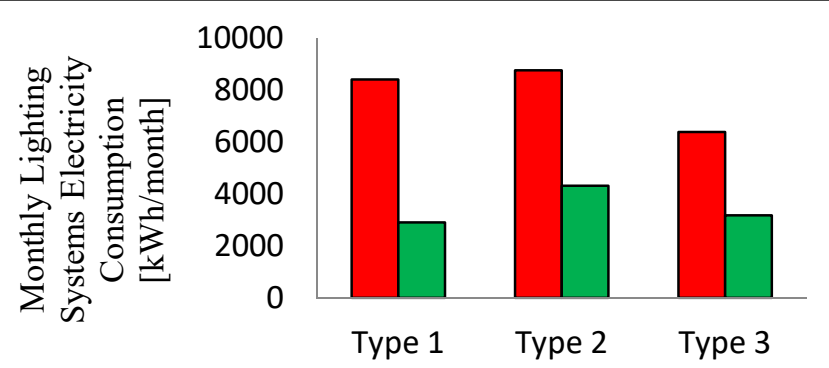

Fig. 2. Energy saving potential of replacing the existent Incandescent Bulbs (Red) with Energy Efficient, LED lights (Green)

In Fig. 3 the energy saving generated by implementing the LED light System is shown with regard to the total electricity consumption of all the twenty six dorms.

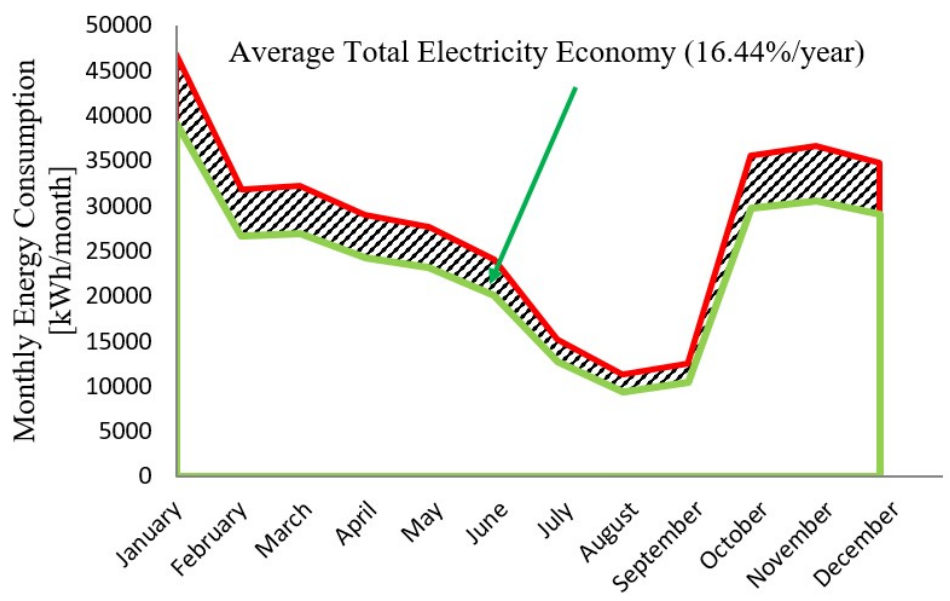

Fig. 3. Electricity consumption in the actual case (red) and in the DMS Program scenario (green) for one Dorm 
By applying the DTC (Discounted Total Cost) criterion, the replacement of the existent lighting system with a LED based one would generate an economy of $\Delta \mathbf{W}_{\mathbf{a}}=\mathbf{1 , 1 8 4 , 1 4 7}$ $\mathbf{k W h} / \mathbf{y e a r}$ (an average total electricity consumption of $16.44 \% /$ year, respectively an associated $55.55 \%$ lighting system economy), respectively a $\triangle \mathrm{DTC}=\mathbf{1 , 2 4 5 , 9 3 3}$ EUR with an associated SPP (Simple Payback Period) of $\mathbf{2 . 4 2}$ years.

\subsection{Testing the DSM Program}

In order to classify and test the economic viability [11-12-13] of the analysed DSM Program, the four scenarios which were presented in Chapter 3 were applied to the threetest methodology presented in Chapter 2.

The results are presented in Table 6.

Table 6. DSM Program Tests results.

\begin{tabular}{|c|c|c|c|}
\hline Scenario & PB [ EUR ] & ESB [ EUR ] & TRC [ EUR ] \\
\hline A & 620,035 & 225,423 & $-122,751$ \\
\hline B & 968,210 & $-122,751$ & $-121,751$ \\
\hline C & 484,105 & 361,354 & $-122,751$ \\
\hline D & 794,123 & 51,336 & $-122,751$ \\
\hline
\end{tabular}

From the end-user's economic perspective, the most attractive scenario is the $2^{\text {nd }}$ one (B), in which the investment cost is fully supported by the energy supply company.

From the energy supply company economic perspective, the most attractive scenario is, as expected, the $3^{\text {rd }}$ one $(\mathrm{C})$, in which the investment cost is fully supported by the end-user.

It can be observed that the TRC test led to a constant value in all four scenarios, as it is used to compare the costs and benefits variation at the society-level (which, for a single program is constant, regardless of how the investment cost or the energy savings are shared).

The tests differentiate from one another by the costs supported by the end-users and by the energy supply companies. In Fig. 4 is shown the test value variation with regard to the share of the investment costs each side supports.

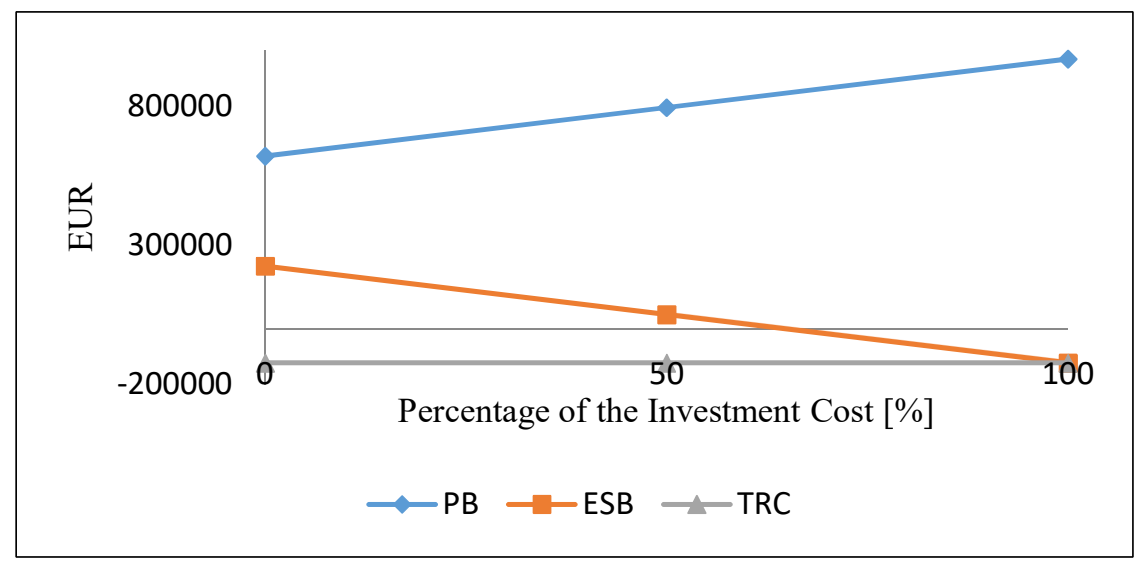

Fig. 4. The DSM Tests variations. 


\subsection{Environmental Impact Analysis}

The Paris Agreement of 2015 (COP21) and the European Union climate change policies boost the development of low $\mathrm{CO}_{2}$ emission technologies.

In order to quantify the Environmental Impact Reduction generated by implementing the analysed DSM Program, the conversion rate of 299,02 tons $\mathrm{CO}_{2} / \mathrm{MWh}$ [14] was considered. The results are presented in Table 7.

Table 7. Environmental Impact Analysis Results

\begin{tabular}{|c|c|c|c|}
\hline Scenario & $\begin{array}{c}\text { Annual Electricity } \\
\text { Consumption } \\
\text { [MWh/year] } \\
\end{array}$ & $\begin{array}{c}\text { Annual Carbon } \\
\text { Footprint } \\
{\left[\mathrm{tCO}_{2} / \text { year] }\right.} \\
\end{array}$ & $\begin{array}{c}\text { Annual Environmental } \\
\text { Impact Reduction } \\
\text { [tCO } \mathrm{CO}_{2} / \text { year] } \\
\end{array}$ \\
\hline Incandescent Lights & $7,478.4$ & $2,236.2$ & - \\
\hline LED Lights & $6,294.3$ & $1,882.1$ & 354.1 \\
\hline
\end{tabular}

The 354.1 tons of $\mathrm{CO} 2 /$ year carbon footprint reduction can mitigate the TRC negative result, as it amounts to a total reduction of 3,541 tons of $\mathrm{CO}_{2}$ for the analysis period, or the equivalent of one typical passenger vehicle worth of carbon dioxide emissions for a year's worth of driving (18.500 km/year) [14-15].

\section{Conclusions}

Lighting has an important effect on the intellectual performance. Thus, by improving the quality of the light one can greatly improve the memorization, the logical thinking, the concentration and the overall intelligence level.

Both DSM Programs and the Romanian Energy Strategy are centred on the end-user. From other countries experience, Romania can adapt the existing models for promoting the energy efficient energy performance improvement actions by using the concept of demand side management.

The first step Romania needs to take in order to facilitate the implementation of DSM Programs consists in creating and developing a legislative framework which can stimulate the energy efficiency improvement and regulate the way in which the energy supply companies can invest in their end-users energy boundaries, from a fiscal point of view.

In the actual economic context of Romania, DSM Programs should be included in the National Energy Policies, oriented towards the efficient use of energy, supported by the main effects that it can generate:

- The decrease of primary energy sources imports (as a direct effect of decreasing the Power Demand and diminishing the Power and Energy Losses);

- The energy performance indicators improvement for the end-users (by utilizing energy efficient equipment and technologies);

- The sensible decrease of the Environmental Impact.

Based on the technical-economic analysis, the LED replacement DSM Program would be able to generate an energy saving of approximatively 1,184 MWh/year and a decrease of the Carbon Footprint of approximatively $354.1 \mathrm{tCO}_{2} /$ year.

The reduction of the Peak Power Demand from an initial value of $433.84 \mathrm{~kW}$ to $197.03 \mathrm{~kW}$ will also lead to an (unquantifiable) benefit of delaying the development and redesign of urban distribution networks. This will also lead to a decrease in transited load (I, respectively $\mathrm{RI}^{2}$ ) throughout the entire transport - distribution networks. 


\section{References}

1. The Romanian Government, National Action Plan in Energy Efficiency, Official Gazette No. 273 bis. (2019)

2. The Romanian Parliament, Energy efficiency Law no 121/2014 (04.08.2014)

3. The Romanian Parliament, Electricity and Natural Gas no 123/2012 (2013)

4. United Nations environment - Global Status Report 2017 - towards a zero-emission, efficient and resilient buildings and construction sector (2018)

5. D. Scripcariu, $\mathrm{PhD}$ Thesis - Improvements in the energy supplier - end-user relationship (1997)

6. Ministry of Regional Development and Public Administration, NP 061-02 Normative for the design and execution of artificial lighting systems in buildings (2002)

7. *** Society of Light and Lightning CIBSE, Code for Lighting

8. *** Illuminating Engineering Society IES, Lighting handbook: the standard lighting guide

9. Public Procurement National Agency, Order no. 2717/318/2018 for the revision of the discount rate (2019)

10. *** http://www.e-ressource.eu - etalux ${ }^{\circledR}$ Lichtsysteme

11. N. Golovanov, I. Iordănescu, P. Postolache, C. Toader, R. Porumb, C. Popescu and L. Lipan, Electric systems and industrial audit elements, N'EGRO Publishing House (2008)

12. D. Scripcariu and M. Scripcariu, Cost effectiveness analysis of Demand-Side Management programmes, UPB Scientific Bulletin, Series C, 60, pp. 291-301 (1998)

13. D. Scripcariu and M. Scripcariu, A modern approach to the energy supplier - end-user relationship and the participation of other organizations in demand-side management programmes, Power Engineering Magazine, 44, pp. 125-129 (1996)

14. *** U.S. Energy Information Administration, https://www.eia.gov/

15. *** The World Bank, http://www.worldbank.org 